\title{
Alternations in Smoking Habits of Active Smoker Health Care Professionals after the 'Law on Prevention of Harmful Effects of Tobacco and Tobacco Products'
}

\section{Mustafa Hamidullah Türkkanı ${ }^{1}$, Leyla Yllmaz Aydın², Tarkan Özdemir ${ }^{3}$}

\author{
${ }^{1}$ Ankara Physical Medicine and Rehabilitation Training and Research Hospital, Ankara \\ ${ }^{2}$ Department of Chest Diseases, Düzce University Faculty of Medicine, Düzce \\ ${ }^{3}$ Çorum Chest Diseases Hospital, Çorum
}

\begin{abstract}
Objective: To evaluate the approaches of active-smoker health care workers to the law on "Prevention and Control of Hazards of Tobacco Products", to determine behavioral changes in smoking and the factors associated with these changes after the law was enacted.

Methods: The population of the study consisted of 1096 health care workers who were active smokers and worked at state hospitals and the 112 emergency service in Çorum. Questionnaire forms were delivered by hand to the participants. The survey was designed with 32 closed-ended questions associated with demographic findings, smoking habits, and the smoking ban. Data were obtained through questionnaires filled out by participants. Statistical Package SPSS 16.0 was used for the analysis.

Results: The response rate was $47.7 \%$. Eighty-five percent of the participants had a positive opinion on the law. In the sociodemographic data, only a higher number of working years in health care was found to be associated with the negative opinion on the ban. As the number of years smoked, pack-years, and addiction level increased, the rate of a positive approach toward the law decreased. Participants who were ashamed of smoking outdoors, who had tried to quit, and who did not smoke in the same environment with children expressed more positive opinions.

Conclusion: Approaches of active smoker health care workers to the smoking ban is similar to society. Health professionals whose role in the fight against tobacco is started by "the responsibility of being a role model" should be taken to smoking control programs as a priority and with a holistic approach.
\end{abstract}

Keywords: Health care workers, tobacco law, Turkey



Received Date: 07.06.2014 Accepted Date: 17.09.2014

Available Online Date: 02.12 .2014

Address for correspondence

Mustafa Hamidullah Türkkanı, Ankara Physical Medicine and Rehabilitation Training and Research

Hospital, Ankara, Turkey

E-mail: mhturkkani@gmail.com

(C) Copyright 2014 Turkish Respiratory Society(TRS) Eurasian J Pulmonol 2014

DOI: $10.5152 /$ ejp.2014.43534

-Available online at www.eurasianjpulmonol.com

\section{INTRODUCTION}

The success in the struggle against risk factors leading to chronic diseases can be reached only with effective national policies and long-term strategies. The programs that aim to change lifestyles for avoiding risk factors leading to chronic diseases affect lifetime and life quality. By taking risk factors under control, the rates of health expenditure and labor loss and deaths associated with these diseases are decreased. One of these risk factors is tobacco products. Today, in the world, 1.3 billion people, $80 \%$ of whom live in developing countries, smoke. About 6 million people die owing to diseases associated with tobacco use, and the economic loss exceeds 0.5 trillion dollars per year (1).

Turkey is ranked third in Europe and seventh in the world with regard to tobacco use. The rate of tobacco use is $37.4 \%$ among male adults, whereas it is $10.7 \%$ among females. In Turkey, 14.8 million people smoke, and approximately 100,000 people die due to the diseases associated with tobacco use every year (1-3). Smoking is the most important health concern in Turkey, and it is the primary cause of preventable deaths.

Turkey signed the "WHO Framework Convention on Tobacco Control" (signed by 171 countries) in 2004. The "National Tobacco Control Program," created accordingly, was declared in December, 2007. In accordance with the program, new arrangements for smoking and tobacco use were performed with changes in Law No. 4207 on the Prevention and Control of Hazards of Tobacco Products (2). With 
the effects of precautions taken for tobacco use, the rate of Turkish smokers aged 15 years and over decreased to $27.4 \%$ in $2008,25.7 \%$ in 2010 , and $23.8 \%$ in 2012 , while it was $47 \%$ in the midst of the 1980 s (3).Turkey has become a country where smoking is forbidden in closed areas, including social refreshment facilities and public transport vehicles, after the smoking ban was enacted on July 19, 2009. The measures taken for preventing passive smoking have been supported at a rate of $95 \%$ (2). At present, Turkey is suggested as an example for other countries in reports of the World Health Organization, owing to its applications of the MPOWER package (Monitor tobacco use, Protect people from tobacco smoke, Offer help to quit tobacco use, Warn about the dangers of tobacco use, Enforce bans on tobacco advertising and promotion, Raise taxes on tobacco) (1).

In our study, we aimed to evaluate the approaches of health care workers who were active smokers and worked in the province of Çorum towards the "Law on Prevention and Control of Hazards of Tobacco Products" and also to determine any behavioral changes in smoking after the law and related factors.

\section{METHODS}

There were 3159 health care providers working at 9 state hospitals and the 112 emergency service in the province of Çorum in 2010. The population of the study consisted of 1096 health care workers who were active smokers. All workers in the health sector (doctor, nurse, health clerk, administrative staff, medical secretary, etc.) were included in the study. Questionnaire forms were delivered to the participants by hand. Data were obtained through the forms, filled out by participants. The questionnaire consisted of 3 parts, including 32 closed-ended questions:

(i) Demographic information: personal and occupational information (gender, age, marital status, the number of children, the number of working years as a health care provider, occupation)

(ii) Questions related to participants' smoking habits (nicotine level of the cigarette they smoke before and after the smoking ban, the number of cigarettes smoked indoors during and after working hours, parental smoking, smoking in the same environment with children, smoking in public places, etc.), knowledge level on the harms of smoking (e.g., its relation with diseases), education level on this issue, reasons for smoking initiation, knowledge level about addiction to smoking, the desire for smoking cessation, addiction level (Fagerstrom test for nicotine dependence), and the reactions of people around them due to smoking.

(iii) Participants' opinions on the smoking ban: "What is your reaction to the smoking ban indoors as a smoker (positive/negative)?"

\section{Statistical Analysis}

Statistical analysis of the data was performed using SPSS 16.0 software. Descriptive statistics were given in percentage, mean, and standard deviation. Chi-square test was used for categorical variables, and t-test was used for continuous variables.

\section{RESULTS}

The response rate of the questionnaire was $47.7 \%(n=523)$. Of participants who completed the questionnaire, $66.9 \%$ was male and
$33.1 \%$ was female. The sociodemographic data of all participants are presented in Table 1. The approaches of health care workers towards the smoking ban indoors are given in Table 2 according to their sociodemographic data. Within this context, no significant difference was observed between age, gender, occupation, the number of children, and marital status and the smoking ban indoors. The only factor that displayed a statistically significant difference was the number of working years as a health care provider. While the number of working years was $10.9 \pm 7.15$ years (mean \pm SD) for participants having positive attitudes toward the smoking ban indoors, it was $13.3 \pm 8$ years for those with negative attitudes toward the ban (mean $\pm S D)(p=0.009)$.

In the evaluation of the relationship between the questions about the participants' attitudes and behaviors toward smoking, the presence of parental smoking, and the reactions of people around them and their positive attitudes toward the smoking ban indoors, it was found that people who felt uncomfortable smoking in public places, who had tried to quit smoking, and who did not smoke in the same environment with children showed positive reactions to the ban $(p<0.001 ; p<0.001 ; p=0.025$ ) (Table 3).

Although all participants were active smokers, $85 \%$ of them evaluated the law positively. However, as the number of smoking years, pack-years, and addiction level increased, the rate of negative reactions to the smoking ban indoors increased $(p=0.042 ; p=0.001$; $\mathrm{p}<0.001$ ) (Tables 4 and 5).

\section{DISCUSSION}

Health care providers, who are role models in society, have an important place in tobacco control programs. Considering their roles in the prevention of tobacco use, we evaluated the approaches of active smoker health care workers to the smoking ban indoors after the law on "Prevention and Control of Hazards of Tobacco Products", their behavioral changes in smoking, and factors associated with these changes after the law, and we found that $85 \%$ of health staff reacted to this ban positively in our study.

\begin{tabular}{|l|c|c|}
\hline \multicolumn{2}{|l|}{ Table 1. Sociodemographic features of the study population } \\
Demographic variables & $\%$ & $\mathbf{n}$ \\
Gender & & \\
Male & 66.9 & 350 \\
Female & 33.1 & 173 \\
Age Distribution & & \\
$20-30$ & 30.8 & 161 \\
$31-40$ & 47.6 & 249 \\
$41-50$ & 17.6 & 92 \\
$>51$ & 4.0 & 21 \\
Occupation & 15.3 & 80 \\
Administrative staff & 49.3 & 258 \\
Health personnel & 35.4 & 185 \\
Service procurement & & \\
\hline
\end{tabular}


Table 2. The opinions of the study population about the smoking ban indoors according to their sociodemographic features

\begin{tabular}{|l|c|c|}
\hline \multirow{2}{*}{ Demographic variables } & \multicolumn{2}{|c|}{$\begin{array}{c}\text { What is your reaction to the smoking } \\
\text { ban indoors as an active smoker? }\end{array}$} \\
\cline { 2 - 3 } Age & Positive (\%) & p value \\
$20-30$ & 87.6 & 0.758 \\
$32-40$ & 84.7 & \\
$41-50$ & 89.1 & \\
$>51$ & 76.2 & \\
Gender & 85.7 & \\
Male & 86.7 & \\
Female & & \\
Occupation & 87.5 & 0.198 \\
Administrative staff & 83.3 & \\
Health personnel & 89.2 & \\
Service procurement & & \\
$\geq 1$ child (n) & 86.4 & \\
Yes (357) & & \\
No (66) & & \\
Marital status (n) & & \\
Married (426) & & \\
Single (97) & & \\
\hline
\end{tabular}

As the number of smoking years, pack-years, and Fagerstrom's nicotine dependence level increased, negative reactions also increased. The only sociodemographic factor that displayed a statistically significant difference in the attitude toward the smoking ban indoors was the number of working years as a health care provider. It was observed that people who felt uncomfortable smoking in public places, who had tried to quit smoking, and who did not smoke in the same environment with children showed positive reactions to the ban.

According to the review, including 22 studies conducted with doctors, nurses, and medical faculty students, and the study of Günay et al. (6), carried out after the enactment of law no. 4207 in Turkey in 1996 , the smoking prevalence was $32.6 \%-66.2 \%$ among doctors, 40.3\%-68.6\% among nurses, and $15.1 \%-36.6 \%$ among medical faculty students (5). In studies conducted after the law on the smoking ban indoors in 2009 and including 1233 primary care physicians and 1063 primary care nurses across Turkey, the smoking prevalence was $34.1 \%$ and $30.1 \%$, respectively $(7,8)$. Moreover, according to a questionnaire study performed with 1217 third-year students in 12 medical faculties, the prevalence of tobacco use was detected to be $28.5 \%(9)$.

These data show that the smoking prevalence of health care workers, who are role models for society, has decreased after the law on tobacco control consistent with the society, but it is still higher than overall society (3).
Table 3. Approach to the smoking ban indoors in accordance with smoking-related features

\begin{tabular}{|c|c|c|}
\hline \multirow[t]{2}{*}{ Question } & \multicolumn{2}{|c|}{$\begin{array}{l}\text { What is your reaction to the smoking } \\
\text { ban indoors as an active smoker? }\end{array}$} \\
\hline & Positive (\%) & p value \\
\hline $\begin{array}{l}\text { Do your parents smoke? } \\
\text { (n) }\end{array}$ & & 0.758 \\
\hline Yes (174) & 87.9 & \\
\hline No (349) & 85.1 & \\
\hline $\begin{array}{l}\text { Does your spouse } \\
\text { smoke? (n) }\end{array}$ & & 0.270 \\
\hline Yes (287) & 89 & \\
\hline No (136) & 85 & \\
\hline $\begin{array}{l}\text { Do you smoke in the } \\
\text { same environment with } \\
\text { your children? (n) }\end{array}$ & & 0.025 \\
\hline Yes (61) & 77 & \\
\hline No (359) & 87.7 & \\
\hline $\begin{array}{l}\text { Have you tried to quit } \\
\text { smoking? (n) }\end{array}$ & & $<0.001$ \\
\hline Yes (326) & 90.8 & \\
\hline No (197) & 78.2 & \\
\hline $\begin{array}{l}\text { Do you feel uncomfortable } \\
\text { when you smoke in public } \\
\text { places? }(n)\end{array}$ & & $<0.001$ \\
\hline Yes (255) & 94.9 & \\
\hline No (268) & 77.6 & \\
\hline $\begin{array}{l}\text { Have you ever been } \\
\text { criticized by children/the } \\
\text { young for smoking? (n) }\end{array}$ & & 0.221 \\
\hline Yes (264) & 87.9 & \\
\hline No (259) & 84.2 & \\
\hline $\begin{array}{l}\text { Have you ever been } \\
\text { criticized for smoking as a } \\
\text { health care worker? (n) }\end{array}$ & & 0.374 \\
\hline Yes (367) & 86.9 & \\
\hline No (156) & 84 & \\
\hline
\end{tabular}

The practice of laws, enacted with political will, can be realized only with a change that begins in individuals and then spreads into society. One of the basic components for creating political determination and social sensitivity in fighting tobacco addiction is health care workers. However, if change occurs with internal motivation and desire instead of external pressure (like making a law) in health staff, as in all individuals, it is more successful.

The results of our study support this point of view. Health care workers who have tried to quit smoking react to this law more positively, because they are the ones who have experienced the stage of action in the change model. 
Table 4. Approach to the smoking ban indoors according to the number of smoking years and pack-years

\begin{tabular}{|l|c|c|c|}
\hline \multirow{2}{*}{} & \multicolumn{3}{|c|}{$\begin{array}{c}\text { "What is your reaction to the smoking } \\
\text { ban indoors as an active smoker?" }\end{array}$} \\
\cline { 2 - 4 } & Positive (\%) & Negative (\%) & p value \\
\hline Smoking years & $14.42 \pm 8.35$ & $16.6 \pm 9.3$ & 0.042 \\
\hline Pack-years & $10.98 \pm 10.43$ & $15.67 \pm 12.11$ & 0.001 \\
\hline
\end{tabular}

Table 5. Approach to the smoking ban indoors according to Fagerstrom's nicotine dependence level

\begin{tabular}{|l|c|c|c|}
\hline \multirow{2}{*}{$\begin{array}{l}\text { Fagerstrom's } \\
\text { nicotine } \\
\text { dependence level }\end{array}$} & \multicolumn{3}{|c|}{$\begin{array}{l}\text { "What is your reaction to the smoking } \\
\text { tban indoors as an active smoker?" }\end{array}$} \\
\cline { 2 - 4 } Low & 89.6 & 10.4 & 0.000 \\
Moditive (\%) & Negative (\%) & p value \\
High & 82.4 & 17.6 & \\
\hline
\end{tabular}

The positive attitudes of health care workers make us think that performing necessary actions for improving and maintaining the stages of change in health care workers who are active smokers is important for social acceptance of the law, because the roles of health care providers in the struggle with smoking begin with the responsibility of being a role model (10).

Therefore, health care workers should be primarily handled in smoking control programs. Comprehensive reforms, including the revision of educational curriculum for "health care workers who interiorize tobacco control," should be developed. Moreover, some activities should be performed in order to prevent smoking behavior in health care workers to be a social norm.

In our study, the health service was evaluated with a holistic approach, and not only doctors and nurses but also other health staff were asked for their opinions. We think that our study is the first from this aspect. In this study, it was found that the type of service provided in the hospital did not change the attitude towards the law. This might have resulted from the high level of acceptance of the law by society and the similarity between our results and other results obtained from other groups of society (11).

However, the fact that there was no significant difference between health care workers, who had been educated professionally in the health sector, and other workers makes us think that postgraduate training programs should be increased. It has been found that postgraduate training is the only factor changing the attitudes of primary care physicians towards the struggle in smoking (12).

\section{Study Limitations}

In our study, a question was asked about the smoking ban indoors included in the law on "Prevention and Control of Hazards of Tobacco Products", which was enacted for preventing passive smoking. No question was asked for other limitations of the law.
Participation in the study was on a voluntary basis. There was no question about personal identification information of the participants in order to increase the reliability of the responses. Therefore, a health care worker who was not involved in the study could not reach any information on the features of active smokers. In addition, the reason for not participating in the study may be some factors, such as a negative attitude toward the law or indifference to the studies conducted for preventing the harms of tobacco products.

The study did not include a control group. The results were compared with studies in the literature.

\section{CONCLUSION}

The attitudes of health care workers who are active smokers toward the bans after the law on "Prevention and Control of Hazards of Tobacco Products" are similar to those of society. Owing to their role of "being a role model for others" in the struggle against tobacco use, health staff should be handled primarily with a holistic approach. Changing behaviors of health care providers and their opinions on tobacco control will contribute to the support for laws to be accepted and implemented.

Ethics Committee Approval: This study is a non-invasive, survey study. Therefore, ethics committee approval was not taken.

Informed Consent: Because the data were obtained through the questionnaire forms filled out by participants, the informed consent was not taken individually.

Peer-review: Externally peer-reviewed.

Author Contributions: Concept - M.H.T., L.Y.A.; Design - L.Y.A.; Supervision M.H.T.; Funding - T.Ö.; Data Collection and/or Processing - T.Ö.; Analysis and/or Interpretation - M.H.T., L.Y.A.; Literature Review - M.H.T.; Writer - M.H.T.; Critical Review - M.H.T., L.Y.A., T.Ö.

Conflict of Interest: No conflict of interest was declared by the authors.

Financial Disclosure: The authors declared that this study has received no financial support.

\section{REFERENCES}

1. WHO Report on the global tobacco epidemic, 2013: enforcingbans on tobacco advertising, promotion and sponsorship. World Health Organization, 2013.

2. Turkey Health Transformation Program Assesment Report (2003 2011), Republic of Turkey Ministry of Health, Ankara, 2012.

3. Turkish Statistical Institute. Global Adult Tobacco Usage Statistics 2012.

4. Turkish Statistical Institute. http://www.tuik.gov.tr/PreHaberBultenleri. do?id=15847 Erişim tarihi: 15 Nisan 2014.

5. Tezcan S, Yardım N. Prevalence of smoking between the doctors, nurses and medical faculty students at some health facilities in Turkey. Tuberk Toraks 2003; 51: 390-7.

6. Günay E, Simşek Z, Kutucularoğlu G, Metinyurt G. Smoking prevalence, nicotine dependence and effects of low cost cigarette sale among military healthcare personal in Turkish Republic of Northern Cyprus. Tuberk Toraks 2010; 58: 393-400.

7. Baltaci D, Bahcebasi T, Aydin LY, Ozturk S, Set T, Eroz R, et al. Evaluation of smoking habits among Turkish family physicians. Toxicol Ind Health 2014; 30: 3-11. [CrossRef]

8. Yilmaz Aydin L, Baltaci D, Ozturk S, Saritas A, Eroz R, Celepkolu T, et al. Smoking habits of nurses and midwives and their attitudes tobacco control; a primary care based study from four major cities of Turkey. Healthmed 2012; 6: 3920-8.

9. Inandi T, Caman OK, Aydin N, Onal AE, Kaypmaz A, Turhan E, et al. Global Health Professions Student Survey - Turkey: second-hand smoke ex- 
posure and opinions of medical students on anti-tobacco law. Cent Eur J Public Health 2013; 21: 134-9.

10. Consensus Guidelines for Diagnosis and Treatment of Smoking Cessation, 2014. Turkish Thoracic Society - Tobacco Control Workgroup, Ankara, 2014.
11. Cakir B, Buzgan T, Com S, Irmak H, Aydin E, Arpad C. Public awareness of and support for smoke-free legislation in Turkey: a national survey using the lot quality sampling technique. East Mediterr Health J 2013; 19: $141-50$ 